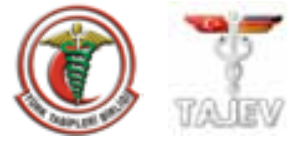

\title{
Evaluation and management of voiding dysfunction after midurethral sling procedures
} Midüretral sling işlemi sonrası işeme disfonksiyonunun değerlendirilmesi ve yönetimi

\author{
Hatice Çelik, Özgür Harmanlı \\ Department of Gynecology and Obstetrics, Tufts University School of Medicine, Baystate Medical Center, USA
}

\begin{abstract}
Midurethral slings have become the most popular surgical procedure for the correction of stress urinary incontinence in women. Urinary retention or obstructive voiding symptoms may arise from partial urethral obstruction as a result of oversuspension of the urethra or exaggerated tension. Fortunately, most cases of voiding dysfunction are transient and resolve spontaneously within days. Clean intermittent self-catheterization is the mainstay of conservative treatment. If symptoms persist, tape mobilization, incision or urethrolysis may be performed. Recurrent stress urinary incontinence may occur in a small group of patients, who may benefit from another incontinence treatment. (J Turkish-German Gynecol Assoc 2012; 13: 123-7)
\end{abstract}

Key words: Incontinence, midurethral sling, voiding dysfunction, urinary retention, urethrolysis

Received: 03 February, 2012

Accepted: 02 April, 2012

\section{Özet}

Midüretral slingler, kadınlarda stress idrar inkontinansının cerrahi tedavisinde en çok tercih edilen işlem haline gelmiştir. Üretranın fazla asılması ya da meşin daha sıkı yerleştirilmesi tam idrar retansiyonuna veya obstrüktif işeme semptomlarına neden olabilir. Akut idrar retansiyonu hemen müdahale gerektirir. Neyse ki, çoğu işeme disfonksiyonu geçicidir ve bir kaç gün ile hafta içinde kendiliğinden çözülür. Temiz, aralıklı self kateterizasyon, konservatif tedavinin temelini oluşturur. Konservatif tedaviye rağmen işeme disfonksiyonu devam ederse meş gevşetilebilir, kesilebilir ya da üretrolizis uygulanabilir. Bu da hastaların küçük bir kısmında tekrar tedaviyi gerektirebilecek düzeyde stres idrar inkontinansına yol açabilir.

(J Turkish-German Gynecol Assoc 2012; 13: 123-7)

Anahtar kelimeler: İnkontinans, midüretral sling, işeme disfonksiyonu, idrar retansiyonu, üretrolizis

Geliş Tarihi: 03 Şubat 2012

Kabul Tarihi: 02 Nisan 2012

\section{Introduction}

Midurethral slings have revolutionized the surgical management of stress urinary incontinence (SUI). Tension-free vaginal tape (TVT), introduced in 1996 by the Ulmsten and Petros, was the first widely available midurethral sling. Since its introduction over 10 years ago, it is estimated that approximately 1 million procedures have been performed worldwide (1). In addition, other techniques such as the suprapubic-arc sling (SPARC), which differs from TVT with respect to the direction of trocar passage, have also gained popularity. In 2001, Delorme described the transobturator tape (TOT) midurethral sling (2). Unlike TVT, it is placed using a transobturator approach rather than a retropubic one. This approach is generally considered to have the advantages of low morbidity, reduced costs and shorter hospital stay $(3,4)$.

Regardless of the technique, anti-incontinence surgery may change bladder outlet resistance. Voiding dysfunction (VD) is a well-recognized complication of midurethral sling procedures. However, the definition of VD is not consistent in the literature. The vague definition of "impaired bladder emptying immediately following surgery" is often used. Some researchers have studied failed voiding after outpatient midurethral sling as the outcome measure for postoperative voiding function. Most cases of mild postoperative voiding dysfunction appear to resolve with expectant or conservative management. Transient urinary retention after TVT has been reported in up to $17 \%$ of patients, but it is important to distinguish this from voiding dysfunction, which is commonly more clinically significant (5). For example, in the Stress Incontinence Surgical Treatment Efficacy Trial (SISTEr), voiding dysfunction was defined as any need for bladder catheterization after 6 weeks, or reoperation for sling takedown (6). The incidence of postoperative retention lasting longer than 4 weeks or requiring intervention following midurethral slings is reported as $2-4 \%$ (7). A recent systematic review and meta-analysis of 33 randomized controlled trials found lower rates of voiding difficulties after transobturator sling when compared to retropubic sling procedures. With regards to comparisons with retropubic tape, TVT and intravaginal slingplasty had similar complication rates, whereas SPARC was complicated by higher rates of voiding lower urinary tract symptoms and reoperations (8). However, the most recent Cochrane review and meta-analysis, which compared the incidence of postoperative VD by the midurethral sling approach, specifically between the transobturator and retropubic approaches, found no difference across 24 trials (9). 


\section{Risk factors}

The debate on the risk factors for VD following midurethral slings continues despite several studies which have focused on this topic.

\section{Demographics and other associated factors}

Due to variable results from different studies, it is difficult to make a decisive conclusion about the demographic predictors of VD after midurethral sling. Sokol et al. (10) found that older age, low body mass index (BMI) and postoperative urinary tract infections (UTI) were independently associated with prolonged time to adequate voiding; however, in this study, a previous history of incontinence surgery was the only independent variable predictive of urinary retention. Barron et al. (11) showed that parity over two and preoperative anxiety were independently associated with successful immediate voiding trial after a TVT procedure in their retrospective review of 126 patients. Barber et al. (12) have found that poor preoperative detrusor function may have a role as well. Women frequently have concurrent abdominal or pelvic surgery at the time of midurethral sling placement. Shukla et al. (13) described a trend toward longterm voiding difficulty when women with low preoperative flow rates underwent concurrent posterior vaginal repairs. Most recently, a multicenter case-control study by Molden et al. (14) reported that preexisting obstructive voiding symptoms, the retropubic approach and concurrent surgery at the time of sling placement were independent risk factors for sling revision.

\section{Urodynamic parameters}

According to several studies, low preoperative peak flow rates or abnormal uroflow can be predictive of postoperative VD after midurethral sling procedures. In a retrospective review of 59 women who underwent TVT, Wang et al. (15) described VD as the following: postvoid residual volume (PVR) of more than $100 \mathrm{ml}$, urinary frequency greater than six times per day or two times per night and urinary stream perceived as abnormal by the patient. In this study, abnormal uroflowmetry, which was defined as flow that did not have a normal configuration or pattern, was found to be an associated factor. A prospective trial of 89 women who underwent the midurethral sling procedure showed low peak flow rate to be the only independent variable for a successful initial voiding trial (16). This is consistent with another retrospective study of 375 patients by Hong et al. (17), which also found lower preoperative peak flow rates as a risk factor. In this study, the parameter for VD was defined as the need to catheterize for 72 hours or longer after surgery. The mean preoperative peak flow rates in the group with and without urinary retention were 22.3 and $29.7 \mathrm{ml} / \mathrm{s}$, respectively. Sung-Tae et al. (18) suggested that a peak flow rate lower than $15 \mathrm{ml} / \mathrm{s}$ was the most predictive variable for postoperative VD.

Some studies investigated the effect of preoperative residual on postoperative VD. In a report of 205 TOT and 213 TVT, Barber et al. (12) found high preoperative PVR to be a consistent risk factor for prolonged postoperative catheterization and slow resumption to normal voiding. In contrast, Minassian et al. (19) retrospectively analyzed 138 patients who underwent antiincontinence surgery, including TVT, Burch or pubovaginal slings and found that patients with early postoperative VD (defined as a residual of $>200 \mathrm{ml}$ at discharge) had lower preoperative PVRs than those who did not (50 vs. $75 \mathrm{ml}$ ).

Barron et al. (20) reported that a Valsalva leak point pressure of more than $60 \mathrm{~cm} \mathrm{H}_{2} \mathrm{O}$ and a maximum urethral closure pressure of more than $20 \mathrm{~cm} \mathrm{H}_{2} \mathrm{O}$ were associated with a successful immediate voiding trial.

Despite the aforementioned studies, numerous other studies have shown no association between postoperative VD and the parameters such as preoperative peak flow rate, preoperative PVR, Valsalva leak point pressureor severe intrinsic sphincter deficiency $(15,18,20-24)$. We were not able to find any report which studied the type of voiding mechanism and detrusor pressures with respect to VD after midurethral slings (25).

\section{Evaluation and diagnosis}

Urethral obstruction after midurethral sling procedure surgery can manifest itself in a variety of ways. Patients may complain of slow urinary stream, splitting or spraying, hesitancy or intermittency with the urine flow, feelings of incomplete emptying, prolonged voiding, straining to void and elevated PVR. Urinary retention may also lead to overflow incontinence, recurrent UTI and painful urination. They may also develop de novo or worsening detrusor overactivity.

The optimal evaluation for patients with postoperative VD is poorly defined in the literature. One should start with a careful pelvic and rectal examination which may identify underlying findings such as abnormal urethral angulation, a foreshortened, non-pliable vagina, non-mobile urethra, pelvic hematoma or fecal impaction. During evaluation, UTI should be ruled out with urinalysis and culture as this can manifest itself with a variety of symptoms. There is a no general consensus on the appropriate PVR volume to diagnose urinary retention. In some studies, PVR cutoff for urinary retention has varied from 100 to $200 \mathrm{ml}(23,26)$. Some authors choose to use a percentage of total volume as an indicator. Techniques to evaluate the adequacy of postoperative bladder emptying also vary tremendously. In a prospective study, Kleeman et al. (27) found that the back fill technique after vaginal prolapse or continence surgery predicted adequate bladder emptying in $91 \%$ of women who voided $50 \%$ or greater of the amount instilled and in $100 \%$ who voided $68 \%$ or greater of the total volume.

The best location for cystourethroscopy and urodynamic studies is controversial. Some authorities advocate videourodynamic studies to diagnose obstruction prior to the reversal of anti-incontinence surgery. Under the ideal circumstances, urodynamic evaluation would differentiate patients with highpressure, low-flow voiding consistent with obstruction and patients with detrusor hypocontractility. In a study by Carr and Webster, urodynamic parameters, previous surgery, time from suspension to urethrolysis and the surgical approach were not good predictors for urethrolysis (28). Cystourethroscopy may be useful to rule out bladder pathology, a hypersuspended bladder neck and foreign bodies such as retained sutures, mesh or stones. In another study by Petrou et al. (29), urethrolysis outcomes were not significantly different when urodynamic parameters were used instead of clinical criteria. At the present 
time, there does not appear to be conclusive evidence to support routine implementation of these tests before any surgical corrective procedure.

\section{Treatment}

\section{Conservative treatment}

Transient postoperative urinary retention has been reported to be within the range of 2.5 to $36 \%$ after surgery for SUI and pelvic organ prolapse (POP) $(30,31)$. Suprapubic catheter placement, which was common before midurethral sling procedure was introduced, has been widely abandoned as prolonged postoperative VD is uncommon after this minimally invasive approach. Temporary Foley catheter drainage, timed voiding, biofeedback, pelvic floor muscle training, clean intermittent self-catheterization, selective medical treatment and urethral dilatation have been successful to some degree in managing postoperative VD. Expectant management is initially appropriate as early retention may be due to postoperative pain, edema and inflammation. Indeed, most patients with transient postoperative urinary retention resume normal voiding following midurethral sling within 1-2 days of the procedure. Return to normal voiding may be delayed for 1-2 weeks in women with a history of prior or concomitant surgery for SUI or POP $(32,33)$. Behavioral treatment begins by encouraging the patient to create a relaxing environment and taking adequate time for voiding. They are instructed to slow down, take a deep breath, relax the body, relax the pelvic floor muscles and wait for the urine to flow. Rushing can inhibit pelvic floor relaxation. Valsalva voiding can increase pelvic floor tension, resulting in incomplete emptying. Anecdotally, some women have benefited from double voiding, or lingering until another detrusor contraction brings about more complete emptying. Perineal or vaginal biofeedback, which can be useful for restoring muscle tension, is a particularly important practice for patients with VD. To facilitate relaxation, these patients can focus more on the relaxation phase, which can be extended with a $1: 2$ ratio or longer as appropriate (34).

Medications play a small role in the treatment of postoperative VD. Diazepam 2-10 mg 1-3 times daily and baclofen 5-10 mg twice daily may also be used in an effort to reduce urethral sphincter and pelvic floor spasm from pain (35). Some may use an $\alpha$-adrenergic antagonist such as terazocin or doxazocin, but there are limited scientific data. These antagonists, which can cause postural hypotension as a significant side effect, are also effective for functional rather than anatomic bladder outlet obstruction. Antimuscarinic medications may be helpful when there are predominantly irritative symptoms and a normal PVR. Specifically, oxybutynin has a combination of antimuscarinic, antispasmodic and local anesthetic properties. However, these medications are contraindicated in women with urinary retention. Vaginal estrogen may be useful for reducing irritative voiding symptoms and recurrent infections (36).

When a patient cannot empty two thirds of her bladder volume within a few hours after an outpatient midurethral sling procedure, the first appropriate step is catheterization. This initial treatment relieves the immediate distress of a full bladder and prevents permanent bladder damage. Continuous transurethral catheterization is less preferable as it is associated with higher rates of UTI, urinary tract irritation, development of bladder calculi and a decrease in bladder capacity over time. Therefore, many institutions adopted teaching patients how to perform self-catheterization either before or after the procedure. If urinary retention with voiding difficulty persists, further treatment will be necessary.

Clean intermittent self-catheterization (CISC) is catheterization performed by the patient or a caregiver on a periodic basis to empty the bladder. It is important to ensure that the bladder never holds more than $500 \mathrm{ml}$ of urine at one time. Bladder distention can result in upper urinary tract reflux, reduced vesical blood flow and UTI. CISC is performed three or four times daily until the residual decreases to less than $100 \mathrm{ml}$, or at most $50 \%$ of the voided volume (37).

Although several reports have shown some benefit with urethral dilatation $(17,38)$, recent reports have proven urethral dilation to be ineffective in most patients with urethral obstruction after TVT procedures. Additionally, repeated urethral dilation may predispose to the development urethral erosion and could induce scarring of the urethra $(24,39,40)$. The place of urethral dilatation for urethral obstruction is yet to be studied in a controlled and randomized fashion.

\section{Surgical treatment}

When these conservative measures fail, surgical intervention is indicated. Fortunately, persistent postoperative VD is a relatively rare complication after midurethral sling placement. Otherwise, some authors have reported that waiting too long may result in unresolved irritative bladder symptoms such as frequency, urgency and urge incontinence (41-43). In the era of traditional pubovaginal slings, which caused VD more often, most surgeons delayed a release procedure until about 3-6 months after the procedure. This has changed to 2 weeks with midurethral slings. Despite some contradicting reports, most of these release procedures have been effective in correcting VD. The mesh still provides support to the urethra laterally even after the obstruction is released at the midline (43).

After midurethral sling procedures, surgical release for refractory postoperative VD procedures has been indicated for $1-2 \%$ of women $(8,44,45)$. This is more common after retropubic sling procedures $(12,44,46)$. Surgical intervention for VD may consist of mobilization, division of the sling or urethrolysis typically through a vaginal approach. Retropubic or a combined vaginal and retropubic technique are rarely necessary. Successful sling mobilization is possible only in early interventions. If the mobilization attempt fails, the sling is cut at the midline or laterally. Urethrolysis entails more dissection and entry into the retropubic space. It may occasionally require mobilization of the urethra from the pubic bone. Unless the release procedure is delayed too long, urethrolysis is rarely necessary for today's slings. Although there are no well-designed and randomized studies comparing the abdominal and vaginal routes, retrospective data indicate success rates approaching 85\%, comparable for retropubic and vaginal routes. Most surgeons prefer transvaginal urethrolysis rather than retropubic or suprameatal approaches (37). 
Mobilization or incision of the midurethral sling is highly successful in improving voiding dynamics and should be considered the first line therapy. In a large review by Klutke et al. (24), 17 of 600 patients (2.8\%) required reoperation for postoperative VD. Tape release was performed at a mean of 64 days after TVT placement and 16 patients remained continent. Hong et al. reported that 4 of 375 (1\%) patients who underwent TVT required tape release or cutting at an average 61 days after the operation and three patients $(0.8 \%)$ underwent a second TVT procedure for recurrent SUI (17). Sling loosening was reported by Nguyen within approximately 1 week after TVT placement. All patients were continent after mobilization, and quality of life scores of the non-voiders did not differ from those of voiders 1 year after surgery (47). In a retrospective study by Price et al. (48), 33 patients required mobilization of TVT to treat postoperative VD. In each case, the TVT was mobilized and loosened without dividing it within 2 weeks after the original procedure. Voiding function subsequently returned to normal in 29 out of 33 women with no recurrence of original stress incontinence. The four remaining women had the tape divided.

Croak et al. (49) reported that TVT tape dissection using a midline incision for obstructive urinary retention was successful in five $(6.4 \%$ of 109 TVTs) patients; four of these (80\%) remained continent. The incision was performed within 4 weeks of initial placement. A nationwide analysis of obstruction after surgery was performed by Laurikanien and Kilholma. A retrospective review of 9040 patients who underwent a TVT procedure was reviewed. The sling was transected at the midline, uni- or bilaterally, or the sling was resected. Forty-nine percent of the patients were completely cured of their retention and four patients (12\%) continued to have retention after lysis. Repeat sling lysis and urethrolysis were options used for refractory retention (50).

A lateral incision technique might be particularly beneficial for avoiding urethral injury in cases whose tape cannot be identified. Long et al. (51) described a technique transecting the tape lateral to the midline on the right side of the periurethral fascia, leaving the tape in the shape of a J underneath the urethra. This procedure had a success rate of $100 \%$ with VD in seven women utilizing a lateral incision, but stress incontinence recurred in $28.6 \%$ of them. Game et al. (52) presented results from a series of 30 women requiring sling lysis with a single lateral incision over a four-year period. $70 \%$ were continent after intervention, and two women developed recurrent SUI. Recently, Kasturi et al. (53) reported $100 \%$ success in 15 women undergoing the $\mathrm{J}$ cut technique for postoperative VD following midurethral sling. Zubke et al. (54) managed three patients with urethral obstruction after TVT with a novel technique. They cut the tape at the midline with a transvaginal approach and sutured the edges of the tape to a Prolene mesh, thus lengthening the tape. All three patients were continent and resumed normal voiding after intervention.

\section{Conclusion}

Surgery for stress incontinence has increasingly shifted towards minimally invasive approaches. Although there are no well- designed and prospective randomized studies which evaluated VD following midurethral sling procedures as the primary outcome, we have gained significant experience over the last decade. Hypersuspension of urethra by sling can cause symptoms of bladder emptying and low urinary tract. Most cases respond to conservative treatment with temporary indwelling catheter and CISC. If symptoms persist, as occurs in 1-2\% of patients, sling mobilization and/or incision almost always resolve the problem. Urethrolysis is rarely necessary for VD after midurethral sling procedures. In a small group of women, another intervention operation may be needed for recurrent stress urinary incontinence.

\section{Conflict of interest}

No conflict of interest was declared by the authors.

\section{References}

1. Ulmsten U, Henriksson L, Johnson P, Varhos G. An ambulatory surgical procedure under local anaesthesia for treatment of female urinary incontinence. Int Urogynecol J Pelvic Floor Dysfunct 1996; 7: 81-5. [CrossRef]

2. Delorme E. Transobturator urethral suspension: miniinvasive procedure in the treatment of stress urinary incontinence in women. Prog Urol 2001; 11: 1306-13.

3. Roumeguère $\mathrm{T}$, Quackels $\mathrm{T}$, Bollens R, de Groote $\mathrm{A}$, Zlotta $\mathrm{A}$, Bossche MV, Schulman C. Trans-obturator vaginal tape (TOT) for female stress incontinence: one year follow-up in 120 patients. Eur Urol 2005; 48: 805-9. [CrossRef]

4. Deval B, Levardon M, Samain E, Rafii A, Cortesse A, Amarenco G, Ciofu C, Haab F. A French multicenter clinical trial of SPARC for stress urinary incontinence. Eur Urol 2003; 44: 254-8. [CrossRef]

5. Guerette NL, Bena JF, Davila GW. Transobturator slings for stress incontinence: using urodynamic parameters to predict outcomes. Int Urogynecol J Pelvic Floor Dysfunct 2008; 19: 97-102. [CrossRef]

6. Lemack GE, Krauss S, Litman H, et al. Normal preoperative urodynamic testing does not predict voiding dysfunction after Burch colposuspension versus pubovaginal sling. J Urol 2008; 180: 2076-80. [CrossRef]

7. Dmochowski RR, Blaivas JM, Gormley EA, Juma S, Karram MM, Lightner DJ, et al. Update of AUA guidline on the surgical management of female stress urinary incontinence. J Urol 2010; 183: 1906-14. [CrossRef]

8. Novara G, Galfano A, Boscolo-Berto R, Secco S, Cavalleri S, Ficarra $\mathrm{V}$, et al. Complication rates of tension-free midurethral slings in the treatment of female stress urinary incontinence: a systematic review and meta-analysis of randomized controlled trials comparing tension-free midurethral tapes to other surgical procedures and different devices. Eur Urol 2008; 53: 288-308. [CrossRef]

9. Ogah J, Cody JD, Rogerson L. Minimally invasive synthetic suburethral sling operations for stress urinary incontinence in women. Cochrane Database Syst Rev 2009; 7: CD006375.

10. Sokol AI, Jelovsek JE, Walters MD, Paraiso MF, Barber MD. Incidence and predictors of prolonged urinary retention after TVT with and without concurrent prolapse surgery. Am J Obstet Gynecol 2005; 192: 1537-43. [CrossRef]

11. Barron KI, Savageau JA, Young SB, Labin LC, Morse AN. Prediction of successful voiding immediately after outpatient mid-urethral sling. Int Urogynecol J Pelvic Floor Dysfunct 2006; 17: 570-5. [CrossRef]

12. Barber MD, Gustilo-Ashby AM, Chen CC, Kaplan P, Paraiso MF, Walters MD. Perioperative complications and adverse events of the MONARCH transobturator tape, compared with tension-free vaginal tape. Am J Obstet Gynecol 2006; 195: 1820-5. [CrossRef]

13. Shukla A, Paul SK, Nishtar A, Bibby J. Factors predictive of voiding problems following insertion of tension-free vaginal tape. Int $J$ Gynaecol Obstet 2007; 96: 122-6. [CrossRef] 
14. Molden S, Patterson D, Tarr M, Sanses T, Bracken J, Nguyen A, Harvie HS, White A, Hammil SA, Murphy M, Rogers RG. Risk factors leading to midurethral sling revision: a multicenter case-control study. Int Urogynecol J 2010; 21: 1253-9. [CrossRef]

15. Wang KH, Neimark M, Davila GW. Voiding dysfunction following TVT procedure. Int Urogynecol J Pelvic Floor Dysfunct 2002; 13: 353-7. [CrossRef]

16. Wheeler TL 2nd, Richter HE, Greer WJ, Bowling CB, Redden DT, Varner RE. Predictors of success with postoperative voiding trials after a mid-urethral sling procedure. J Urol 2008; 179: 600-4. [CrossRef]

17. Hong B, Park S, Kim HS, Choo MS. Factors predictive of urinary retention after a tension-free vaginal tape procedure for female stress urinary incontinence. J Urol 2003; 170: 852-6. [CrossRef]

18. Sung-Tae Cho, Hyeong-Cheol Song, Ha-Jong Song, Young-Goo Lee, $\mathrm{Ki}$-Kyung Kim. Predictors of postoperative voiding dysfunction following transobturator sling procedures in patients with stress urinary incontinence. INJ 2010; 14: 26-33.

19. Minassian VA, Al-Badr A, Drutz HP, Lovatsis D. Tension-free vaginal tape, Burch, and slings: are there predictors for early postoperative voiding dysfunction? Int Urogynecol J Pelvic Floor Dysfunct 2004; 15: 183-7. [CrossRef]

20. Barron KI, Savageau JA, Young SB, Labin LC, Morse AN. Prediction of successful voiding immediately after outpatient mid-urethral sling. Int Urogynecol J Pelvic Floor Dysfunct 2006; 17: 570-5. [CrossRef]

21. Gamble TL, Botros SM, Beaumont JL, Goldberg RP, Miller JJ, Adeyanju O, Sand PK. Predictors of persistent detrusor overactivity after transvaginal sling procedures. Am J Obstet Gynecol. 2008; 199: 696.e1-7.

22. Kobak WH, Walters MD, Piedmonte MR. Determinants of voiding after three types of incontinence surgery: a multivariable analysis. Obstet Gynecol 2001; 97: 86-91. [CrossRef]

23. Houwert RM, Venema PL, Aquarius AE, Bruinse HW, Kil PJ, Vervest HA. Predictive value of urodynamics on outcome after midurethral sling surgery for female stress urinary incontinence. Am J Obstet Gynecol 2009; 200: 649.e1-649.e12.

24. Klutke C, Siegel S, Carlin B, Paszkiewicz E, Kirkemo A, Klutke J. Urinary retention after tension-free vaginal tape procedure: incidence and treatment. Urology 2001; 58: 697-701. [CrossRef]

25. Lemack GE, Krauss S, Litman H, FitzGerald MP, Chai T, Nager C, et al. Normal preoperative urodynamic testing does not predict voiding dysfunction after Burch colposuspension versus pubovaginal sling. J Urol 2008; 180: 2076-80. [CrossRef]

26. Duckett JR, Patil A, Papanikolaou NS. Predicting early voiding dysfunction after tension-free vaginal tape. J Obstet Gynaecol 2008; 28: 89-92. [CrossRef]

27. Kleeman S, Goldwasser S, Vassallo B, Karram M. Predicting postoperative voiding efficiency after operation for incontinence and prolapse. Am J Obstet Gynecol 2002; 187: 49-52. [CrossRef]

28. Carr LK, Webster GD. Voiding dysfunction following incontinence surgery: diagnosis and treatment with retropubic or vaginal urethrolysis. J Urol. 1997; 157: 821-3. [CrossRef]

29. Petrou SP, Brown JA, Blaivas JG. Suprameatal transvaginal urethrolysis. J Urol 1999; 161: 1268-71. [CrossRef]

30. Pulvino JQ, Duecy EE, Buchsbaum GM, Flynn MK. Comparison of 2 techniques to predict voiding efficiency after inpatient urogynecologic surgery. J Urol 2010; 184: 1408-12. [CrossRef]

31. Vierhout ME. Prolonged catheterization after vaginal prolapse surgery. Acta Obstet Gynecol Scand 1998; 77: 997. [CrossRef]

32. Romanzi LJ, Chaikin DC, Blaivis JG. The effect of genital prolapse on voiding. J Urol 1999; 161: 581-58. [CrossRef]

33. Dietz HP, Haylen BT, Vancaillie TG. Female organ prolapse and voiding dysfunction. Int Urogynecol J Pelvic Floor Dysfunct 2002; 13: 282-8. [CrossRef]

34. Burgio KL. Behavioral treatment of urinary incontinence, voiding dysfunction, and overactive bladder. Obstet Gynecol Clin N Am 36 2009; 36: 475-91.
35. Stanton SL, Cardozo LD, Kerr-Wilson R. Treatment of delayed onset of spontaneous voiding after surgery for incontinence. Urology 1979; 13: 494-6. [CrossRef]

36. Saks EK, Arya LA. Pharmacologic management of urinary incontinence, voiding dysfunction, and overactive bladder. Obstet Gynecol Clin N Am 36 2009; 19: 490-5.

37. Karram MM, Siddighi S. Surgical and nonsurgical approaches to treat voiding dysfunction following antiincontinence surgery. Curr Opin Obstet Gynecol 2007; 19:490-495 [CrossRef]

38. Karram MM, Segal JL, Vassallo BJ, Kleeman SD. Complications and untoward effects of the tension-free vaginal tape procedure. Obstet Gynecol 2003; 101: 929-32. [CrossRef]

39. Rardin CR, Rosenblatt PL, Kohli N, Miklos JR, Heit M, Lucente VR. Release of tension-free vaginal tape for treatment of refractory postoperative voiding dysfunction. Obstet Gynecol 2002; 100: 898-902 [CrossRef]

40. Vassallo BJ, Kleeman SD, Segal J, Karram MM. Urethral erosion of a tension-free vaginal tape. Obstet Gynecol 2003; 101: 1055-8. [CrossRef]

41. Leng WW, Davies BJ, Tarin T, Sweeney DD, Chancellor MB. Delayed treatment of bladder outlet obstruction after sling surgery: association with irreversible bladder dysfunction. J Urol 2004; 172: 1379-81. [CrossRef]

42. Sweeney DD, Leng WW. Treatment of postoperative voiding dysfunction following incontinence surgery. Curr Urol Rep 2005; 6: 365-70. [CrossRef]

43. South MMT, Wu JM, Webster GD, Weidner AC, Roelands JJ, Amundsen CL. Early vs late midline sling lysis results in greater improvement in lower urinary tract symptoms. Am J Obstet Gynecol 2009; 200: 564.e1-e5.

44. Richter HE, Albo ME, Zyczynski HM, Kenton K, Norton PA, Sirls LT, et al. Retropubic versus Transobturator. Midurethral Slings for Stress Incontinence. N Engl J Med 2010; 362: 2066-76. [CrossRef]

45. Sung VW, Schleinitz MD, Rardin CR, MD1, Ward RM, Myers DL. Comparison of Retropubic versus Transobturator Approach to Midurethral Slings: A Systematic Review and Meta-AnalysisAm J Obstet Gynecol 2007; 197: 3-11. [CrossRef]

46. Stanford EJ, Paraiso MFR. A comprehensive review of suburethral sling procedure complications. J Min Invas Gynecol. 2008; 15: 132-45. [CrossRef]

47. Nguyen JN. Tape mobilization for urinary retention after tension-free vaginal tape procedures. Urology 2005; 66: 523-6. [CrossRef]

48. Price N, Slack A, Khong SY, Currie I, Jackson S. The benefit of early mobilisation of tension-free vaginal tape in the treatment of postoperative voiding dysfunction. Int Urogynecol J Pelvic Floor Dysfunct 2009; 20: 855-8. [CrossRef]

49. Croak AJ, Schulte V, Peron S, Klingele C, Gebhart J, Lee R. Transvaginal tape lysis for urinary obstruction after tension-free vaginal tape placement. J Urol 2003; 169: 2238-41. [CrossRef]

50. Laurikainen E, Kiilholma PA. nationwide analysis of transvaginal tape release for urinary retention after tension-free vaginal tape procedure. Int Urogynecol J Pelvic Floor Dysfunct 2006; 17: 111-9. [CrossRef]

51. Long CY, Lo TS, Liu CM, Hsu SC, Chang Y, Tsai EM. Lateral excision of tension-free vaginal tape for the treatment of iatrogenic urethral obstruction. Obstet Gynecol 2004; 104: 1270-4. [CrossRef]

52. Gamé X, Soulié M, Malavaud B, Seguin P, Vazzoler N, Sarramon JP, et al. Prog Treatment of bladder outlet obstruction secondary to suburethral tape by section of the tape. Urol 2006; 16: 67-71.

53. Kasturi S, Hale DS. "J" cut of sling for postoperative voiding dysfunction following synthetic midurethral slings. Int Urogynecol J 2011; 22: 933-6. [CrossRef]

54. Zubke W, Becker S, Krämer B, Wallwiener D. Persistent urinary retention after tension-free vaginal tape: a new surgical solution. Eur J Obstet Gynecol Reprod Biol 2004; 115: 95-8. [CrossRef] 